\title{
SUBSTRATO DE CRESCIMENTO DO FUNGO Metarhizium anisopliae INFLUENCIA NA VIRULÊNCIA CONTRA LARVAS DE Aedes aegypti
}

\author{
Aline Teixeira Carolino ${ }^{1}$ \\ Thais Berçot Pontes Teodoro² \\ Simone Azevedo Gomes ${ }^{3}$ \\ Richard Ian Samuels ${ }^{4}$
}

Resumo: O presente estudo investigou a virulência dos isolados 4556 e ESALQ 818 do fungo M. anisopliae crescidos nos substratos arroz parboilizado e nos meios de cultivo BDA (para o isolado 4556) e SDA (para o isolado ESALQ 818). Ensaios de virulência foram realizados com larvas de Aedes aegypti provenientes de ovos coletados no campo. Os ovos foram colocados na água e deram origem as larvas que foram utilizadas nos experimentos. Os conídios de M. anisopliae (ambos isolados) crescidos nos diferentes substratos foram formulados em Tween 80 e utilizados na concentração de $1 \times 10^{7}$ conídios $\mathrm{ml}^{-1}$. O estudo constatou que os dois isolados crescidos no arroz parboilizado foram mais virulentos para larvas de campo de A. aegypti. Apenas 7,5\% das larvas tratadas com os conídios do isolado 4556 crescidos no arroz sobreviveram e no meio de cultivo BDA a sobrevivência das larvas foi de 65,\%, após 24 horas de infecção. As larvas tratadas com conídios do isolado ESALQ 818 produzidos no arroz apresentaram 52,5\% de sobrevivência e as tratadas com conídios produzidos no meio SDA apresentaram sobrevivência de $85 \%$, após 24 horas de infecção.

Palavras-chave: Fungos entomopatogênicos; Conídios; Dengue.

\footnotetext{
${ }^{1}$ Ciências Biológicas/Universidade Estadual Norte Fluminense, Brasil. E-mail: carolinoat@gmail.com.br. ${ }^{2}$ Ciências Biológicas/Universidade Estadual Norte Fluminense, Brasil. E-mail: thaisbercot@yahoo.com.br. ${ }^{3}$ Ciências Biológicas/Universidade Estadual Norte Fluminense, Brasil. E-mail: simoneazgomes@yahoo.com.br. ${ }^{4}$ Zoologia/Universidade Estadual Norte Fluminense, Brasil. E-mail: richardiansamuels@gmail.com.
} 